\title{
Mechanistic study of secondary organic aerosol components formed from nucleophilic addition reactions of methacrylic acid epoxide
}

\author{
A. W. Birdsall ${ }^{1, *}$, C. R. Miner ${ }^{1}$, L. E. Mael ${ }^{1}$, and M. J. Elrod ${ }^{1}$ \\ ${ }^{1}$ Department of Chemistry and Biochemistry, Oberlin College, Oberlin, Ohio, USA \\ * currently at: Department of Chemistry, University of Wisconsin-Madison, Madison, Wisconsin, USA
}

Correspondence to: M. J. Elrod (mjelrod@oberlin.edu)

Received: 17 July 2014 - Published in Atmos. Chem. Phys. Discuss.: 1 August 2014

Revised: 21 October 2014 - Accepted: 30 October 2014 - Published: 8 December 2014

\begin{abstract}
Recently, methacrylic acid epoxide (MAE) has been proposed as a precursor to an important class of isoprene-derived compounds found in secondary organic aerosol (SOA): 2-methylglyceric acid (2-MG) and a set of oligomers, nitric acid esters, and sulfuric acid esters related to 2-MG. However, the specific chemical mechanisms by which MAE could form these compounds have not been previously studied with experimental methods. In order to determine the relevance of these processes to atmospheric aerosol, MAE and 2-MG have been synthesized and a series of bulk solution-phase experiments aimed at studying the reactivity of MAE using nuclear magnetic resonance (NMR) spectroscopy have been performed. The present results indicate that the acid-catalyzed MAE reaction is more than 600 times slower than a similar reaction of an important isoprenederived epoxide, but is still expected to be kinetically feasible in the atmosphere on more acidic SOA. The specific mechanism by which MAE leads to oligomers was identified, and the reactions of MAE with a number of atmospherically relevant nucleophiles were also investigated. Because the nucleophilic strengths of water, sulfate, alcohols (including 2-MG), and acids (including MAE and 2-MG) in their reactions with MAE were found to be of similar magnitudes, it is expected that a diverse variety of MAE + nucleophile product species may be formed on ambient SOA. Thus, the results indicate that epoxide chain reaction oligomerization will be limited by the presence of high concentrations of nonepoxide nucleophiles (such as water); this finding is consistent with previous environmental chamber investigations of the relative humidity dependence of 2-MG-derived oligomerization processes and suggests that extensive oligomerization may not be likely on ambient SOA because of other competitive MAE reaction mechanisms.
\end{abstract}

\section{Introduction}

Due to isoprene's significant contribution to global secondary organic aerosol (SOA) (Carlton et al., 2009; Hallquist et al., 2009), the atmospheric chemical mechanisms by which this volatile substance is converted into aerosol-phase components have recently received intense scrutiny. Previous studies using environmental chamber experiments have shown that isoprene-derived SOA can be formed through an oxidation pathway that begins with methacrolein, a firstgeneration product of isoprene oxidation, and results in the formation of 2-methylglyceric acid (2-MG), a compound that has been observed in laboratory-generated and ambient atmospheric SOA (Surratt et al., 2006; Jaoui et al., 2008; Edney et al., 2005; Szmigielski et al., 2007; Zhang et al., 2011). Further environmental chamber studies have established that methacryloylperoxynitrate (MPAN) is a second-generation oxidation product in this pathway (Surratt et al., 2010).

In addition to 2-MG itself, related compounds have also been observed on SOA. In environmental chamber experiments, oligomers, nitric acid esters, and sulfuric acid esters structurally related to 2-MG have been characterized using a variety of chromatographic and mass spectroscopic techniques (A. W. H. Chan et al., 2010; Surratt et al., 2007; Szmigielski et al., 2007; Hatch et al., 2011a; GómezGonzález et al., 2008; Zhang et al., 2011). In one case, the observation of a dimer containing two 2-MG subunits connected via an ester linkage in ambient aerosol has been reported (Jaoui et al., 2008). These species are of particular interest in understanding SOA composition because they possess volatilities even lower than that of 2-MG, due to increased molecular weights and/or the presence of highly polar nitrate and sulfate groups. 
Recent atmospheric chamber experiments suggest that water content (i.e., relative humidity - RH) plays a large role in determining the extent of oligomerization of species containing 2-MG subunits. Under conditions of very low water content $(\mathrm{RH}<2 \%)$, the photooxidation of isoprene was observed to lead to 2-MG-derived oligoesters up to eight units in length (Nguyen et al., 2011). On the other hand, a $69 \%$ reduction in 2-MG oligomer formation was observed under high water content $(\mathrm{RH}=90 \%)$ conditions. Similarly, a second investigation of isoprene-derived SOA found that the extent of 2-MG-derived oligomerization decreased by almost a factor of 4 as the water content was increased from 13 to $88 \%$ RH (Zhang et al., 2011). A third study of methacroleinderived SOA determined that 2-MG-derived oligomerization was extensive at $<10 \% \mathrm{RH}$, with up to five $2-\mathrm{MG}$ units in the oligomers (A. W. H. Chan et al., 2010).

The mechanisms by which sulfate esters, nitrate esters, and oligoesters containing 2-MG are formed, and the conditions necessary for efficient formation, are currently unknown. One possible source of these compounds is via acidcatalyzed reactions of 2-MG itself. In particular, a Fischer esterification mechanism would allow for oligomeric chains of 2-MG to be formed or for nitrate and sulfate ester formation in the presence of those inorganic ions. However, previous kinetics measurements suggest that, under the typical range of aerosol conditions, Fischer esterification of 2-MG proceeds too slowly to account for the extent of oligomer formation observed in atmospheric chamber experiments (Birdsall et al., 2013).

Recent atmospheric chamber studies and field observations have demonstrated that an epoxide species, methacrylic acid epoxide (MAE), may be, via hydrolysis reaction, the precursor to 2-MG formation (Lin et al., 2013). Therefore, it is also quite possible that the various classes of esters containing 2-MG units identified in atmospheric chamber experiments may also be products of MAE reactions, rather than of reactions solely involving 2-MG. Indeed, in an analogous situation, laboratory studies of isoprene-derived SOAphase chemistry (Lin et al., 2012; Surratt et al., 2010; Darer et al., 2011; Hu et al., 2011; Cole-Filipiak et al., 2010) and field observations of SOA (Hatch et al., 2011b; Surratt et al., 2010; M. N. Chan et al., 2010) for isoprene-dominated situations have uncovered evidence that many of the individual isoprene backbone-retaining chemical species observed are the result of the SOA-phase reactions of isoprene epoxydiols (IEPOX) (Paulot et al., 2009). Therefore, it is of interest to explore the potential mechanisms by which methacroleinderived epoxide intermediates, such as MAE, may lead to the previously observed methacrolein backbone-containing SOA components (i.e., 2-MG-related species).

In this paper, we report measurements of the bulk-phase reaction of MAE with a number of atmospherically relevant nucleophiles (including MAE itself and 2-MG), using nuclear magnetic resonance (NMR) as the analytic technique. The mechanistic and kinetic data obtained from these exper- iments are then used to assess the potential nature of MAE reaction on ambient SOA.

\section{Experimental}

\subsection{Synthesis of reactants}

\subsubsection{Synthesis of MAE}

Both MAE and 2-MG were synthesized following a procedure previously developed to synthesize 2-MG (Birdsall et al., 2013). All precursor compounds were obtained from Sigma-Aldrich and used as obtained, with given purities, unless otherwise noted. Methacrylic acid (MA) $(99 \%, 20 \mathrm{~mL}$, 1 eq.) was added to a $500 \mathrm{~mL}$ round-bottom flask containing reagent-grade dichloromethane $(200 \mathrm{~mL})$ and a magnetic stir bar. An excess of meta-chloroperoxybenzoic acid ( $m \mathrm{CPBA})$ ( $\leq 77 \%, 55 \mathrm{~g}, 1.25$ eq.) was then added as the oxidant. Monitoring the reaction progress with ${ }^{1} \mathrm{H}$ NMR showed complete epoxidation was achieved after 7 days of stirring at room temperature $\left(22^{\circ} \mathrm{C}\right)$, or $24 \mathrm{~h}$ under reflux $\left(40^{\circ} \mathrm{C}\right)$. After filtering off excess $m \mathrm{CPBA}$ (and the oxidation product metachlorobenzoic acid ( $m \mathrm{CBA})$ ) with successive vacuum filtration and gravity filtration steps until the solution contained no visible precipitate, the crude, dilute epoxide product was divided into two fractions of equal volume: one fraction was worked up to provide purified MAE, while in the other fraction, the MAE was hydrolyzed and isolated to provide 2-MG.

In order to isolate MAE, further extraction and purification steps were performed, following a literature procedure (Grill et al., 2006). Complete rotary evaporation of dichloromethane resulted in a white slurry. The slurry was transferred to a flask with a minimum of cold $\left(0^{\circ} \mathrm{C}\right)$ deionized water (approximately $40 \mathrm{~mL}$ ) and briefly swirled by hand. Because MAE is quite water soluble, it partitioned into the aqueous phase. The remaining solid (presumably $m \mathrm{CBA}$ ) was removed via consecutive vacuum and gravity filtration steps and discarded. The remaining aqueous solution underwent rotary evaporation ( 15 Torr pressure, $40^{\circ} \mathrm{C}$ bath) until no further volume loss was observed, resulting in a clear, viscous liquid.

In part because the ${ }^{1} \mathrm{H}$ NMR spectrum revealed that the aqueous extraction resulted in significant hydrolysis of MAE to 2-MG, MAE was then isolated using flash column chromatography (Costa et al., 2013) with diethyl ether (Fisher Scientific) as the eluent. The isolated MAE was confirmed to be $>95 \%$ pure by ${ }^{1} \mathrm{H}$ NMR. Due to the observed slow selfreaction of MAE at room temperature, MAE was stored at $-80^{\circ} \mathrm{C}$ when not in use.

\subsubsection{Synthesis of 2-MG}

2-MG was formed from the other fraction of dilute, crude MAE by simultaneous aqueous extraction and acid-catalyzed hydrolysis, as described previously (Birdsall et al., 2013). In 
some cases, a solid was observed to have precipitated out of the crude MAE solution during storage. In this case, another gravity filtration was performed before proceeding with the hydrolysis procedure. The solution was then transferred to an Erlenmeyer flask, and $50 \mathrm{~mL}$ of $0.2 \mathrm{M} \mathrm{HClO}_{4}$ (prepared from $70 \% \mathrm{HClO}_{4}$ ) was added to the mixture to form a biphasic solution with precipitate formation observed in the interfacial region. The solution was stirred continuously, and, if necessary, sparing amounts of additional dichloromethane was added over time as dichloromethane evaporated in order to maintain two clearly defined phases. Over 8 days, MAE partitioned into the aqueous phase and hydrolyzed into 2-MG. The solution was gravity filtered, and the aqueous phase was isolated using a separatory funnel. The strong acid (i.e., $\mathrm{HClO}_{4}$ but not 2-MG) component of the solution was stoichiometrically neutralized with $\mathrm{NaOH}$ solution $(97 \%$, $10 \mathrm{~mL}, 1.0 \mathrm{M}$ ). The dilute 2-MG solution was transferred to a glass trap with a magnetic stir bar and attached to a vacuum system. Water was removed by gradually lowering the pressure to $<1$ Torr, with vigorous stirring and immersion in a water bath maintained at $295 \mathrm{~K}$, until no more volume loss or drop in vacuum pressure were observed (at approximately 500-600 mTorr). This endpoint was achieved after approximately $2 \mathrm{~h}$ of vacuum pumping. No further purification of the resulting 2-MG was found to be necessary (as in the case of MAE, the purity was in excess of $95 \%$ ), though as discussed in Birdsall et al. (2013), the self-catalyzed conversion of 2-MG via Fischer esterification to oligomer products was observed to appear with an initial concentration of $2 \%$ and roughly $7 \%$ after 6 months of storage at room temperature $(295 \mathrm{~K})$. To avoid even this very slow process, 2-MG was also stored at $-80^{\circ} \mathrm{C}$ when not in use.

\subsection{NMR technique}

A variety of nuclear magnetic resonance (NMR) spectra were collected to identify and quantify the products of reactions of MAE. A $400 \mathrm{MHz}$ Varian NMR spectrometer was used to collect all spectra, using default experimental parameters except where noted. Built-in auto-lock and gradient shim routines were used before collecting each spectrum, except when increased temporal resolution was necessary for kinetics measurements. In these cases, the auto-lock and gradient shim routines were performed only once, immediately before the first of a series of spectra were collected. Chemical shifts were calibrated relative to the solvent HDO peak (4.79 ppm) for all ${ }^{1} \mathrm{H}$ spectra, and relative to DSS (0.0 ppm) (or by using secondary standards that were referenced to DSS) for all ${ }^{13} \mathrm{C}$ spectra. For experiments performed in aqueous solution, $\mathrm{D}_{2} \mathrm{O}$ (Cambridge Isotope Laboratories) was used as a solvent. Deuterated methanol, $\mathrm{CD}_{3} \mathrm{OD}$, and deuterated acetic acid, $\mathrm{CD}_{3} \mathrm{COOD}$ (both Cambridge Isotope Laboratories), were also used as solvents (and nucleophiles) in some experiments as well.
The kinetics of MAE hydrolysis were determined using an NMR-based technique previously developed in our lab (Darer et al., 2011; Birdsall et al., 2013). For these experiments, ${ }^{1} \mathrm{H}$ spectra were collected with eight scans $(30 \mathrm{~s})$ which gave large enough signal-to-noise ratios to be able to follow MAE reactant loss over more than an order of magnitude of relative concentration.

Product studies of reactions of MAE required the collection of $1-\mathrm{D}{ }^{13} \mathrm{C}$ NMR spectra, as well as several 2-D spectroscopic techniques: ${ }^{1} \mathrm{H}-{ }^{1} \mathrm{H}$ correlation spectroscopy (COSY), ${ }^{1} \mathrm{H}-{ }^{13} \mathrm{C}$ heteronuclear multiple quantum correlation spectroscopy (HMQC), and ${ }^{1} \mathrm{H}^{13} \mathrm{C}$ heteronuclear multiplebond coherence spectroscopy (HMBC) (Braun et al., 1998). This suite of NMR experiments provided information about single- and multiple-bond couplings necessary to determine bond connectivity in product molecules and resolve overlapping peaks in 1-D NMR spectra.

Built-in pulse sequences were used for all experiments; an increased number of scans were often used to enhance the signal-to-noise ratio. COSY spectra were collected using the gDQCOSY pulse sequence, which includes both a doublequantum filter and a gradient pulse for improved signal and fewer artifacts. The pulse sequences used to collect HMQC and HMBC spectra, gHMQC and gHMBCAD, respectively, both contained a gradient pulse as well, while the gHMBCAD sequence also included an adiabatic pulse. When necessary to enhance the resolution and signal of HMBC and HMQC spectra, the number of increments and scans per increment were increased from the defaults, up to a maximum of 1024 increments and 32 scans per increment. For experiments querying carbon atoms (1-D ${ }^{13} \mathrm{C}$ NMR, HMBC), the spin-lattice relaxation time (T1) was increased when necessary, from $1 \mathrm{~s}$ to $2-10 \mathrm{~s}$, to improve the signal strength of quaternary carbon peaks.

\subsection{MAE hydrolysis kinetics}

The kinetics of MAE hydrolysis were measured by using ${ }^{1} \mathrm{H}$ NMR to monitor the hydrolysis of MAE to 2-MG of solutions containing known amounts of MAE, water, and acid. For each hydrolysis kinetics experiment, $10 \mu \mathrm{L}$ of MAE was dissolved in $990 \mu \mathrm{L}$ of $0.10-1.0 \mathrm{M} \mathrm{D}_{2} \mathrm{SO}_{4}$ in $\mathrm{D}_{2} \mathrm{O}$ in a $10 \mathrm{~mL}$ beaker, with stirring, for $2-3 \mathrm{~min}$. The $1 \mathrm{~mL}$ solution was then transferred to a $5 \mathrm{~mm}$ NMR tube and ${ }^{1} \mathrm{H}$ spectra were collected as the hydrolysis progressed, with the time intervals between spectral collection adjusted according to the rate of the reaction. 
Table 1. Initial reactants' mole fractions $(X)$ and final products' mole fractions $(Y)$ for the different experiments performed. The product mole fractions were determined with an estimated relative error of $25 \%$.

\begin{tabular}{lllllllll}
\hline Exp. & $X_{\text {MAE }}$ & Nuc 1 & $X_{\text {Nuc1 }}$ & Nuc 2 & $X_{\text {Nuc2 }}$ & $Y_{\text {MAE-MAE }}$ & $Y_{\text {MAE-Nuc1 }}$ & $Y_{\text {MAE-Nuc2 }}$ \\
\hline 1 & 0.003 & $\mathrm{SO}_{4}^{2-}$ & 0.0045 & $\mathrm{D}_{2} \mathrm{O}$ & 0.992 & & 0.05 & 0.95 \\
2 & 0.005 & ${\mathrm{~d}-A A^{\mathrm{a}}}^{2}$ & 0.492 & $\mathrm{D}_{2} \mathrm{O}$ & 0.492 & & 0.28 & 0.72 \\
3 & 0.026 & $\mathrm{~d}-\mathrm{AA}$ & 0.487 & $\mathrm{~d}-\mathrm{MeOH}^{\mathrm{b}}$ & 0.487 & & 0.16 & 0.84 \\
$4^{\mathrm{c}}$ & $>0.8$ & & & & & & & \\
5 & 0.110 & $2-\mathrm{MG}$ & 0.890 & & & 0.02 & 0.19 & \\
6 & 0.670 & $\mathrm{H}_{2} \mathrm{O}$ & 0.330 & & & 0.33 & 0.26 & \\
7 & 0.021 & $2-\mathrm{MG}$ & 0.461 & $\mathrm{MeOH}$ & 0.054 & & 0.09 & 0.06 \\
\hline
\end{tabular}

a d-AA: deuterated acetic acid $\left(\mathrm{CD}_{3} \mathrm{COOD}\right)$

b d-MeOH: deuterated methanol $\left(\mathrm{CD}_{3} \mathrm{OD}\right)$

c Experiment 4 was a "neat" sample of MAE contaminated with at most 0.20 mole fraction water. Because of the uncertainty in the water content of this sample, experiment 4 was not used in the quantitative determination of relative nucleophilities, but rather was used to establish NMR assignments and to aid in the mechanistic interpretation of the MAE reactions.

\subsection{MAE nucleophilic addition product identification and relative nucleophilicity determination methods}

\subsubsection{Deuterated solvent nucleophiles/direct NMR analysis method}

For the cases where deuterated nucleophiles were available, MAE was added to the deuterated nucleophile solutions and the reaction was directly monitored in the NMR tube in a process very similar to the method used for the hydrolysis kinetics study.

Three experimental solutions were prepared (the compositions of the various solutions are given in Table 1): to assess the relative nucleophilicity of sulfate and water in their reactions with MAE, a solution consisting of $10 \mu \mathrm{L}$ of MAE and $600 \mu \mathrm{L}$ of $1 \mathrm{MD}_{2} \mathrm{SO}_{4}$ in $\mathrm{D}_{2} \mathrm{O}$ was prepared (experiment 1 ). To assess the relative nucleophilicity of acetic acid and water in their reactions with MAE, a solution consisting of $10 \mu \mathrm{L}$ of MAE and $1000 \mu \mathrm{L}$ of an equimolar $\mathrm{CD}_{3} \mathrm{COOD} / \mathrm{D}_{2} \mathrm{O}$ solution was prepared (experiment 2). To assess the relative nucleophilicity of acetic acid and methanol in their reactions with MAE, a solution consisting of $50 \mu \mathrm{L}$ of MAE and $1000 \mu \mathrm{L}$ of an equimolar $\mathrm{CD}_{3} \mathrm{COOD} / \mathrm{CD}_{3} \mathrm{OD}$ solution was prepared (experiment 3). Upon the addition of MAE, the solutions were stirred for 2-3 min, at which point the samples were transferred to $5 \mathrm{~mm}$ NMR tubes and spectra were collected.

\subsubsection{Normal isotope nucleophiles/aliquot NMR analysis method}

For the cases where deuterated nucleophiles were not available, MAE was added to the normal isotope nucleophile solution, stirred for 2-3 min, and the reaction mixture was stored in a vial at room temperature. Small-volume aliquots of these solutions were periodically withdrawn from the vials, added to about $700 \mu \mathrm{L}$ of $\mathrm{D}_{2} \mathrm{O}$, and the resulting mixtures were loaded into NMR tubes and spectra were collected.
Four experimental solutions (Table 1) were prepared: to assess the potential oligomer forming reactions of MAE, a neat MAE sample was monitored (experiment 4). To assess the relative nucleophilicity of MAE and 2-MG in their reactions with MAE, a solution consisting of $50 \mu \mathrm{L}$ of MAE and $0.551 \mathrm{~g}$ of 2-MG was prepared (experiment 5). To assess the relative nucleophilicity of MAE and water in their reactions with MAE, a solution consisting of $300 \mu \mathrm{L}$ of MAE and $29 \mu \mathrm{L}$ of water (a $2: 1 \mathrm{MAE} / \mathrm{H}_{2} \mathrm{O}$ molar ratio) was prepared (experiment 6). To assess the relative nucleophilicity of 2-MG and methanol in their reactions with MAE, a solution consisting of $40 \mu \mathrm{L}$ of MAE and $0.788 \mathrm{~g}$ of an equimolar 2-MG $/ \mathrm{H}_{2} \mathrm{O}$ solution that had a small amount of methanol added (the actual methanol content of the solution was determined via NMR methods) was prepared (experiment 7).

\section{Results}

\subsection{MAE and 2-MG NMR identification}

${ }^{1} \mathrm{H}$ NMR peak assignments for the species observed in the MAE hydrolysis experiments were consistent with the MAE assignments (Lin et al., 2013) and 2-MG assignments (Birdsall et al., 2013) previously reported. As discussed in the Supplement to Birdsall et al. (2013), sets of peaks postulated to arise from diastereomers were observed in the ${ }^{1} \mathrm{H}$ and ${ }^{13} \mathrm{C}$ spectra in a manner that is consistent with the observations of Espartero et al. (1996) for similar lactic acid-derived species. The complete ${ }^{1} \mathrm{H}$ and ${ }^{13} \mathrm{C}$ chemical shift assignments for MAE and 2-MG are given in Figs. 1 and 2, respectively.

\subsection{MAE hydrolysis kinetics}

The rate-determining step of acid-catalyzed epoxide hydrolysis is typically the opening of the epoxide ring, preceded by protonation of the epoxide that acts as a pre-equilibrium step. Because of this pre-equilibrium, the differential rate law can 

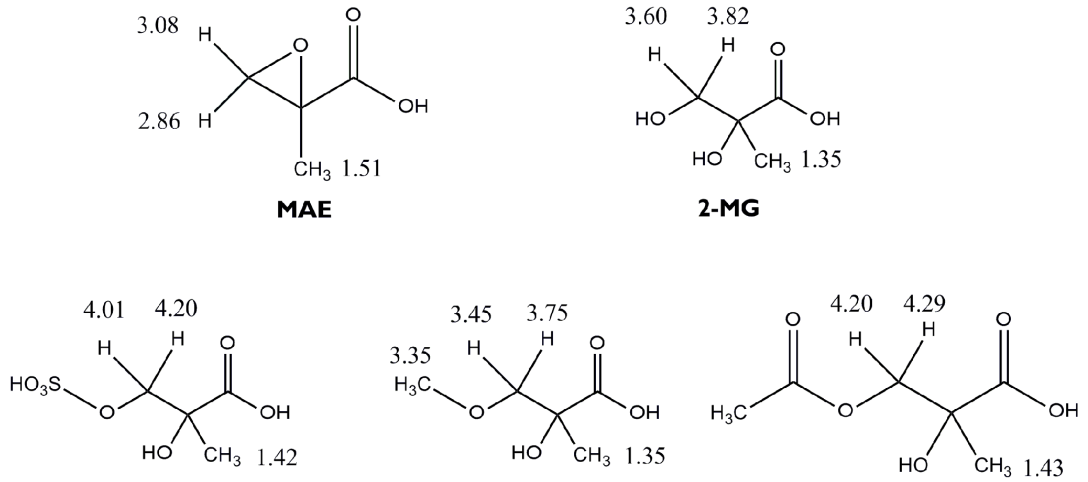

MAE-sulfuric acid ester

MAE-acetic acid ester

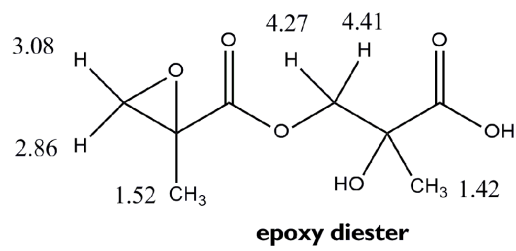

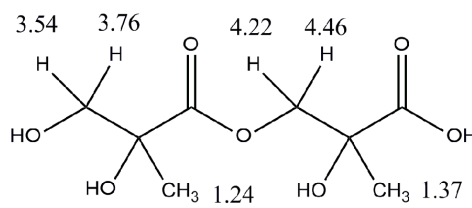

diester

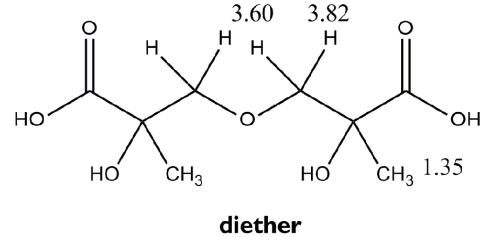

Figure 1. ${ }^{1} \mathrm{H}$ NMR chemical shift assignments for MAE-related species.

be written in terms of its dependence on $\mathrm{H}^{+}$and MAE,

$-\frac{d[\mathrm{MAE}]}{d t}=k\left[\mathrm{H}^{+}\right][\mathrm{MAE}]$,

where $k$ is the rate constant and [MAE] and $\left[\mathrm{H}^{+}\right]$are the molar concentrations of $\mathrm{MAE}$ and $\mathrm{H}^{+}$, respectively. If the actual acid does not also act as a nucleophile, its concentration is constant over time, allowing for the substitution

$k^{\prime}=k\left[\mathrm{H}^{+}\right]$,

where $k^{\prime}$ is the pseudo-first-order rate constant. Sulfuric acid was used as the acid source in these experiments. Although deprotonated forms of sulfuric acid can potentially compete with water in the nucleophilic addition process (and thus potentially decrease the acid concentration over time), the use of relatively low concentrations of sulfuric acid led to a situation in which the nucleophilic addition of water dominated for all conditions (as confirmed by the quantification of the nucleophilic addition products formed). Thus, from Eqs. (1) and (2), the integrated pseudo-first-order rate law is obtained,

$\ln \frac{[\mathrm{MAE}]}{[\mathrm{MAE}]_{0}}=-k^{\prime} t$, where $[\mathrm{MAE}]_{0}$ is the initial concentration of MAE. Fig-

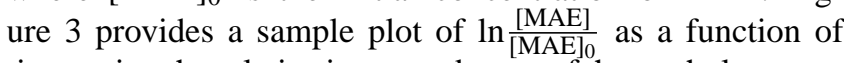
time, using the relative integrated areas of the methylene protons of $2-\mathrm{MG}$ and MAE in ${ }^{1} \mathrm{H}$ NMR spectra to calculate $[\mathrm{MAE}] /[\mathrm{MAE}]_{0}$.

The bimolecular rate constant is determined from the extracted $k^{\prime}$ values over a range of acid concentrations, using the relationship in Eq. (2) (Fig. 4). The range of acidities accessible to our experiments was bounded on the lower end by the increasing significance of the presence of trace sources of acidity (postulated to arise from MAE / 2-MG), and on the upper end by the susceptibility of sulfate ester formation at high sulfuric acid concentrations. The extracted rate constant $k$ (and 1 standard deviation statistical error) was found to be $(5.91 \pm 0.45) \times 10^{-5} \mathrm{M}^{-1} \mathrm{~s}^{-1}$. Due to possible kinetic isotope effects, the presently reported rate constant (measured in deuterated solvent conditions) may differ from the rate constant appropriate for aerosol environments (normal isotope solvent conditions). While this effect was not investigated in the present study, a previous acid-catalyzed epoxide kinetics investigation (Eddingsaas et al., 2010) estimated that deuterated solvent conditions lead to rate constants that are either 


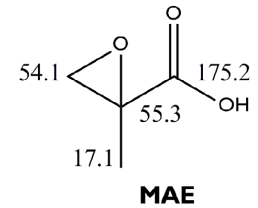<smiles>O=C(O)C(O)(CO)C(=O)O</smiles>
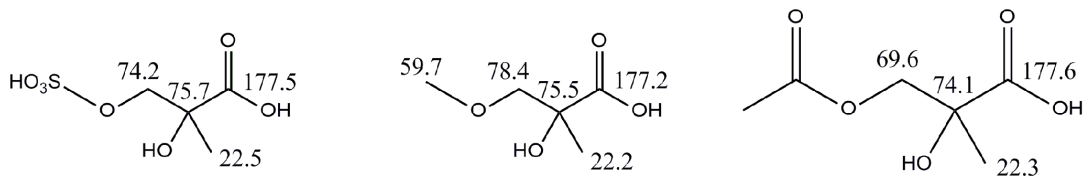

MAE-sulfuric acid ester

MAE-methanol ether

MAE-acetic acid ester<smiles>CC(C)(OC(=O)COC(=O)C(C)(O)C(=O)O)C(=O)O</smiles><smiles>CC(O)(COC(=O)C(C)(O)C(=O)O)C(=O)O</smiles><smiles>CC(O)(COC=[14C]C([14CH3])(O)C(=O)O)C(=O)O</smiles>

Figure $2 .{ }^{13} \mathrm{C}$ NMR chemical shift assignments for MAE-related species.

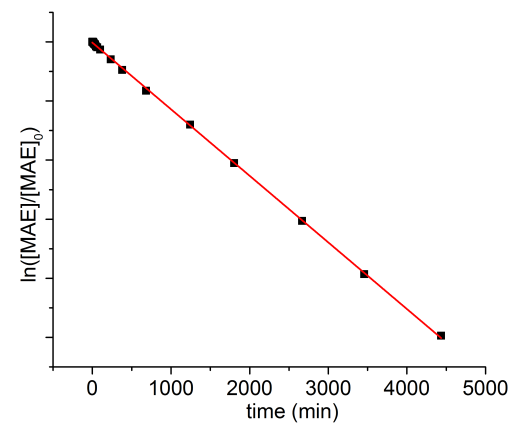

Figure 3. Pseudo-first-order decay of MAE in $1.0 \mathrm{M} \mathrm{D}_{2} \mathrm{SO}_{4}$.

equal to those for normal isotope solvent conditions (for $\mathrm{S}_{\mathrm{N}} 2$ like mechanisms) to rate constants as much as a factor of two larger than for normal isotope solvent conditions (for $\mathrm{S}_{\mathrm{N}} 1$ like mechanisms).

The newly obtained rate constant for MAE hydrolysis can be compared to previously published structurereactivity trends in bulk-phase epoxide hydrolysis kinetics for molecules with alcohol groups (Cole-Filipiak et al., 2010; Minerath et al., 2009). In general, it was found that hydroxyl substitution on a carbon atom adjacent to the epoxide ring reduced the hydrolysis rate constant by up to three orders of

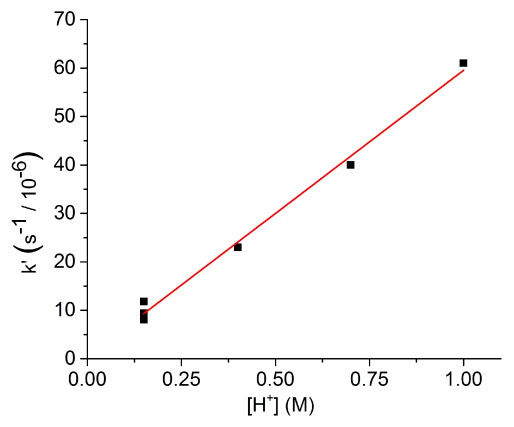

Figure 4. Determination of acid-catalyzed MAE hydrolysis rate constant.

magnitude, presumably due to inductive effects that destabilize the carbocation intermediate.

Table 2 compares the rate constant for MAE hydrolysis to those of other structurally similar epoxides and/or atmospherically relevant epoxides. The epoxide without hydroxyl or carboxyl substitution, 2-methyl1,2-epoxypropane, has the largest rate constant of all species. The hydroxyl-substituted species, 3-methyl-3,4epoxy-1,2-butanediol (IEPOX-1) and 2-methyl-2,3-epoxy1,4-butanediol (IEPOX-4) have rate constants 2-3 orders of magnitude smaller, in line with the predicted structurereactivity relationship. On the other hand, the carboxyl- 
Table 2. Acid-catalyzed rate constants for primary-tertiary epoxide hydrolysis with varying substitution.

\begin{tabular}{ll}
\hline Epoxide & $k\left(\mathrm{M}^{-1} \mathrm{~s}^{-1}\right)$ \\
\hline 2-Methyl-1,2-epoxypropane & $8.7^{\mathrm{a}}$ \\
IEPOX-1 (3-methyl-3,4-epoxy-1,2-butanediol) & $0.0079^{\mathrm{b}}$ \\
IEPOX-4 (2-methyl-2,3-epoxy-1,4-butanediol) & $0.036^{\mathrm{b}}$ \\
MAE (2-methyl-2,3-epoxypropanoic acid) & $0.0000591^{\mathrm{c}}$ \\
\hline
\end{tabular}

a Minerath and Elrod (2009),

${ }^{b}$ Cole-Filipiak et al. (2010),

c this work.

substituted species, MAE, has a rate constant more than 600 times smaller than the atmospherically relevant IEPOX-4 species. A recent computational study predicted that MAE hydrolysis will proceed at a rate 1700 times slower than IEPOX-4 (Piletic et al., 2013), a result in good agreement with the present experimental finding. The computational study also suggested that the reason for the large difference in reactivity is due to a fundamental difference in reaction mechanism: while IEPOX-4 primarily undergoes nucleophilic attack at its tertiary epoxide carbon atom, the computational work suggested that MAE will primarily undergo nucleophilic reaction at its primary epoxide carbon atom.

\subsection{Identification of nucleophilic addition mechanisms for MAE reacting with sulfate, methanol, and acetic acid}

Figure 5 depicts the two possible generic nucleophilic addition pathways for MAE, one leading to a tertiary addition product, which was not observed in any case, and one leading to a primary addition product, which was observed in every case. For clarity concerning the position of nucleophilic addition, these mechanisms are drawn as sequential reaction $\left(\mathrm{S}_{\mathrm{N}} 1\right.$-like $)$ mechanisms. While it is likely that these mechanisms are more accurately represented by concerted $\left(\mathrm{S}_{\mathrm{N}} 2\right.$-like) formalism, the actual mechanism may lie somewhere on a continuum between the sequential and concerted pathways (Whalen, 2005; Eddingsaas et al., 2010; Piletic et al., 2013). It should be noted, however, that the preceding hydrolysis kinetics analysis does not depend on the actual mechanistic pathway (since nucleophilic water is in excess and has an unchanging concentration in those experiments, the two mechanisms are experimentally indistinguishable). Since 2-MG has both alcohol and carboxylic acid functional groups that could potentially act as nucleophiles, methanol and acetic acid were chosen as model systems to explore the similarities and differences for these two different types of nucleophiles. In addition, MAE + sulfate was studied, as 2MG-related sulfate esters have been identified in previous atmospheric chamber experiments (Gómez-González et al., 2008; Surratt et al., 2007; Hatch et al., 2011a). The NMR evidence for the exclusive presence of a primary addition prod-
Table 3. MAE reaction relative nucleophilic strength scale. The relative nucleophilicities were determined with an estimated uncertainty of about $50 \%$, due to uncertainties in both reactant and product mole fraction measurements.

\begin{tabular}{ll}
\hline Nucleophile & Relative nucleophilicity \\
\hline Acetic acid & 0.6 \\
MAE & 1 (by definition) \\
2-MG & 1.2 total $=0.6$ (carboxylic acid) \\
& +0.6 (primary alcohol) \\
Water & 1.6 \\
Methanol & 5.0 \\
$\mathrm{SO}_{4}^{2-}$ & 18 \\
\hline
\end{tabular}

uct for all three nucleophiles - methanol, acetic acid, and sulfate - is discussed in detail below.

\subsubsection{MAE + sulfate reaction}

This reaction was carried out in a $1 \mathrm{MD}_{2} \mathrm{SO}_{4}$ solution (experiment 1), with sulfuric acid serving as both the source of the nucleophilic sulfate ions $\left(\left[\mathrm{SO}_{4}^{2-}\right]=0.75 \mathrm{M}\right.$ according to the Extended Aerosol Inorganics Model (E-AIM); Clegg et al., 1998) and the source of acidity $\left(\left[\mathrm{D}^{+}\right]=1.2 \mathrm{M}\right.$ according to E-AIM) needed for catalysis. The relatively fast observed product-forming kinetics indicated that the sulfate ester product was forming as the result of fast $\mathrm{MAE}+\mathrm{SO}_{4}^{2-}$ reaction as opposed to slow Fischer esterification $2-\mathrm{MG}+\mathrm{SO}_{4}^{2-}$ reaction (Birdsall et al., 2013). To determine which epoxide carbon the sulfate group had attacked (the two nucleophilic addition pathways are shown in Fig. 5), the ${ }^{1} \mathrm{H}$ chemical shifts of the sulfate species were compared to those of 2-MG. The relative $\mathrm{CH}_{3}$ and $\mathrm{CH}_{2}$ shifts of the sulfate ester compared to those of $2-\mathrm{MG}$ ( $\sim 0.4 \mathrm{ppm}$ downfield) are the same as the Fischer esterification-produced sulfate ester observed by Birdsall et al. (2013), which was determined through analysis of ${ }^{13} \mathrm{C}$ NMR spectra to be the primary sulfate. Furthermore, based on previous work with sulfates structurally related to 1,2,3,4-butanetetrol, the ${ }^{1} \mathrm{H}$ NMR spectrum of the tertiary sulfate would be expected to differ significantly, with the $\mathrm{CH}_{2}$ peaks in the MAE-derived tertiary sulfate expected to appear 0.1 to $0.2 \mathrm{ppm}$ downfield of the $2-\mathrm{MG} \mathrm{CH}_{2}$ peaks (Minerath and Elrod, 2009). Such peaks were not observed, and thus the NMR evidence points to the exclusive formation ( $<0.5 \%$ of initial MAE reactant amount) of a primary sulfate addition product. As discussed in Sect. 3.2, a previous computational study identified the primary addition mechanism as the more kinetically facile pathway (Piletic et al., 2013), a finding quite consistent with the present experimental results. The complete ${ }^{1} \mathrm{H}$ and ${ }^{13} \mathrm{C}$ chemical shift assignments for this species are given in Figs. 1 and 2, respectively. 


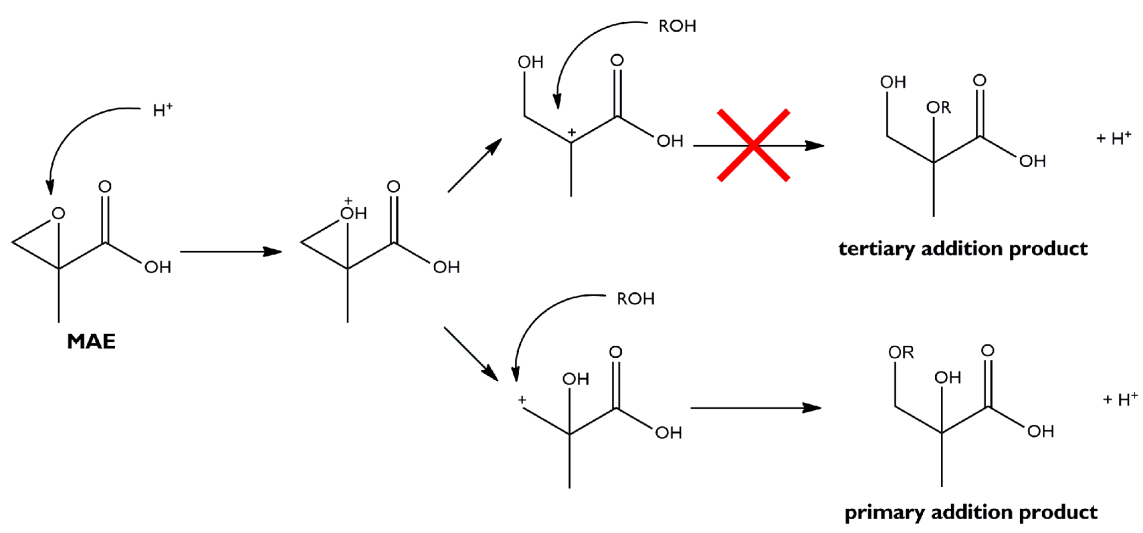

Figure 5. Generalized MAE nucleophilic addition mechanism (the tertiary addition product was not observed for any MAE + nucleophile reactions).

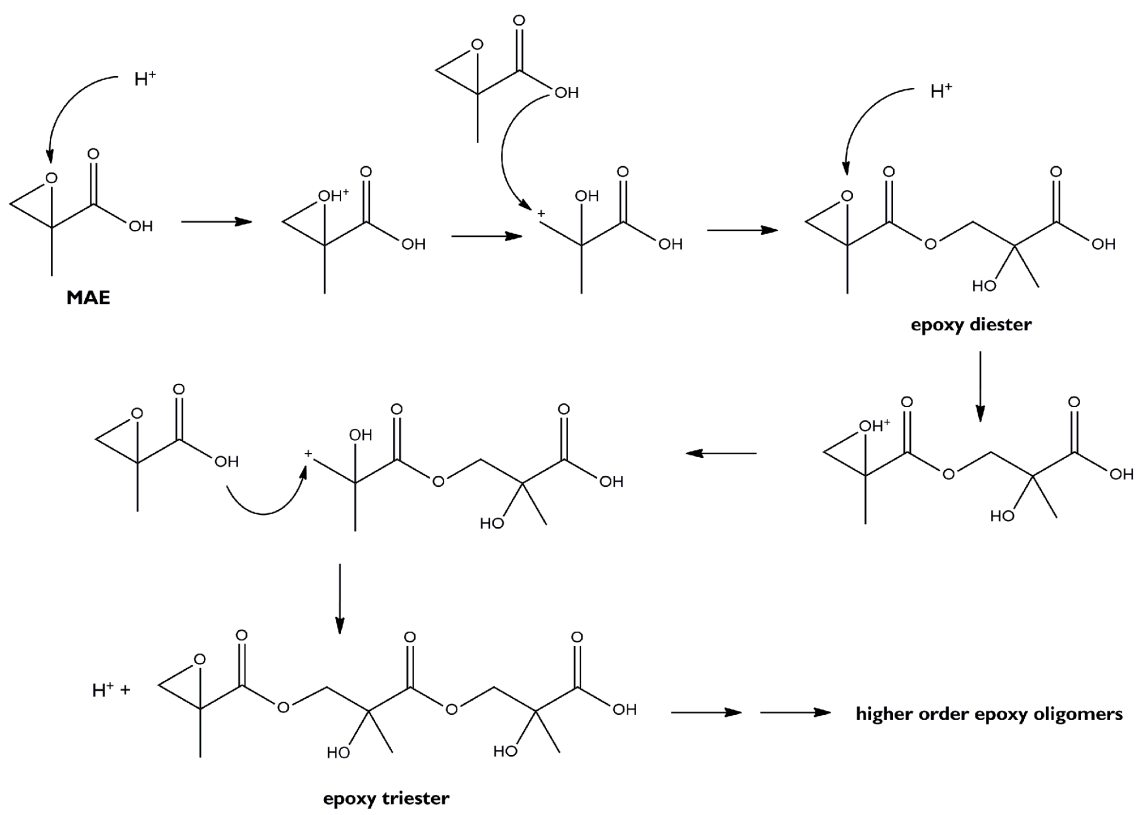

Figure 6. MAE oligomerization (via epoxy chain reaction) mechanism.

\subsubsection{MAE + methanol reaction}

In the methanol nucleophile experiments, either $\mathrm{CD}_{3} \mathrm{COOD}$ (experiment 3) or 2-MG (experiment 7) provided the acidity needed for the catalysis of the reaction. For the experiment using $\mathrm{CD}_{3} \mathrm{OD}$ (experiment 3), new peaks (at 3.45 and $3.75 \mathrm{ppm}$ ) located near the 2-MG peaks (at 3.60 and $3.82 \mathrm{ppm}$ ) were observed, consistent with the formation of a single ether isomer from the nucleophilic addition of methanol to MAE. However, in order to establish the nucleophilic attack position of the methanol moiety, it was also useful to investigate the spectra of the normal isotope (experiment 7). In particular, having observable protons in the ${ }^{1} \mathrm{H}$ NMR spectrum from the nucleophilic methanol species allowed for long-range coupling between the added methanol moiety and the carbon atom that it attacked in the MAE moiety to be observed. This long-range coupling, observable in an HMBC spectrum, allowed for the definitive structural assignment of a primary or tertiary nucleophilic attack product to be made. In particular, the HMBC spectrum showed a single three-bond coupling between the protons on the methanol moiety and primary carbon atom on the MAE moiety. Had the tertiary addition product formed, a three-bond coupling between the protons on the methanol moiety and the tertiary carbon would have been observed in the HMBC spectrum. Therefore, as for the sulfate addition case, the NMR spectrum indicates the sole formation of a methanol primary addition product. The complete ${ }^{1} \mathrm{H}$ and ${ }^{13} \mathrm{C}$ chemical shift assignments for this species are given in Figs. 1 and 2, respectively. 


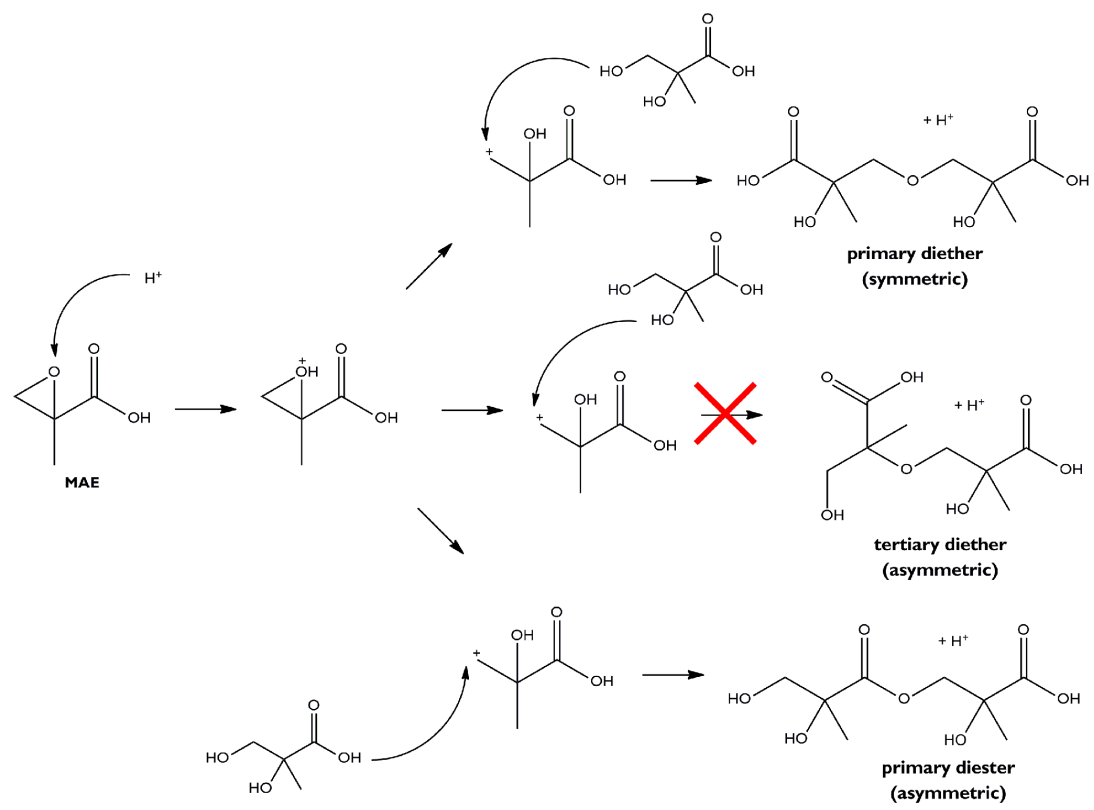

Figure 7. Specific MAE + 2-MG nucleophilic addition mechanisms (the tertiary alcoholic OH group on 2-MG was not observed to participate in nucleophilic addition reactions).

\subsubsection{MAE + acetic acid system}

In the acetic acid nucleophile experiments, $\mathrm{CD}_{3} \mathrm{COOD}$ provided the acidity needed for the catalysis of the reaction. Once again, the NMR evidence showed that the single primary addition species was the sole product formed. The partial ${ }^{1} \mathrm{H}$ and ${ }^{13} \mathrm{C}$ chemical shift assignments for this species are given in Figs. 1 and 2, respectively (the acetic acid moiety proton and carbon atoms were not observed due to the exclusive use of $\mathrm{CD}_{3} \mathrm{COOD}$ ). In the $\mathrm{MAE}+\mathrm{CD}_{3} \mathrm{COOD} / \mathrm{D}_{2} \mathrm{O}$ experiment (experiment 2), the actual $\mathrm{pH}$ of the solution could be calculated from the initial concentrations and the known $\mathrm{pKa}$ of acetic acid $(\mathrm{pH}=1.8)$. If the reaction were following a sequential $\mathrm{S}_{\mathrm{N}}$ 1-like mechanism (in which the nucleophile concentration does not affect the overall rate of the reaction), the formal second-order rate constant would be expected to be identical to the value determined in the hydrolysis experiment. On the other hand, if the reaction were following a concerted $\mathrm{S}_{\mathrm{N}}$ 2-like mechanism, the phenomenological second-order rate constant would be expected to be larger if acetic acid were a stronger nucleophile than water, and smaller if acetic acid were a weaker nucleophile than water. The actual second-order rate constant determined from experiment 2 was $5.0 \times 10^{-5} \mathrm{M}^{-1} \mathrm{~s}^{-1}$. Since this value is within the experimental uncertainty of the hydrolysis rate constant, an $\mathrm{S}_{\mathrm{N}} 1$-type mechanism cannot be ruled out. On the other hand, assuming an $\mathrm{S}_{\mathrm{N}}$ 2-type mechanism, this slightly smaller rate constant could be interpreted as indicating that acetic acid is a somewhat weaker nucleophile than water. However, since the reaction may actually be operating along a continuum between the $\mathrm{S}_{\mathrm{N}} 1$ - and $\mathrm{S}_{\mathrm{N}} 2$-like mechanisms, it is quite difficult to draw any definitive conclusions from this result.

\subsection{Identification of nucleophilic addition mechanisms for MAE reacting with MAE and 2-MG}

Based on the demonstrated preference for MAE to react at its primary epoxide carbon (as outlined above in Sect. 3.3), it was assumed, as a preliminary analysis provision, that the nucleophiles MAE and 2-MG will also attack exclusively at the MAE primary carbon. Figure 6 depicts the specific nucleophilic addition of one MAE molecule acting as a nucleophile (through the $\mathrm{OH}$ group on its carboxylic acid moiety) to another MAE molecule. This particular mechanism is capable of producing the kind of higher order oligomers (via chain reaction of the epoxy ester products with MAE) observed in previous environmental chamber studies (Zhang et al., 2011; A. W. H. Chan et al., 2010a; Nguyen et al., 2011). Figure 7 depicts the three possible specific nucleophilic addition options for a 2-MG molecule attacking MAE. If 2MG uses its carboyxlic acid $\mathrm{OH}$ group, a primary diester (a molecule in which two 2-MG subunits are connected via a single ester linkage) would be expected to form (this particular species can also be produced via the acid-catalyzed Fischer self-esterification of 2-MG, a process previously studied in our lab; Birdsall et al., 2013). On the other hand, if 2-MG uses either of its alcoholic $\mathrm{OH}$ groups, either a primary or a tertiary diether (molecules in which two 2-MG subunits are connected via a single ether linkage) would be expected to form. The nomenclature used to identify the various species in Figs. 1, 2, 6, and 7 is intended to highlight the mechanistic 


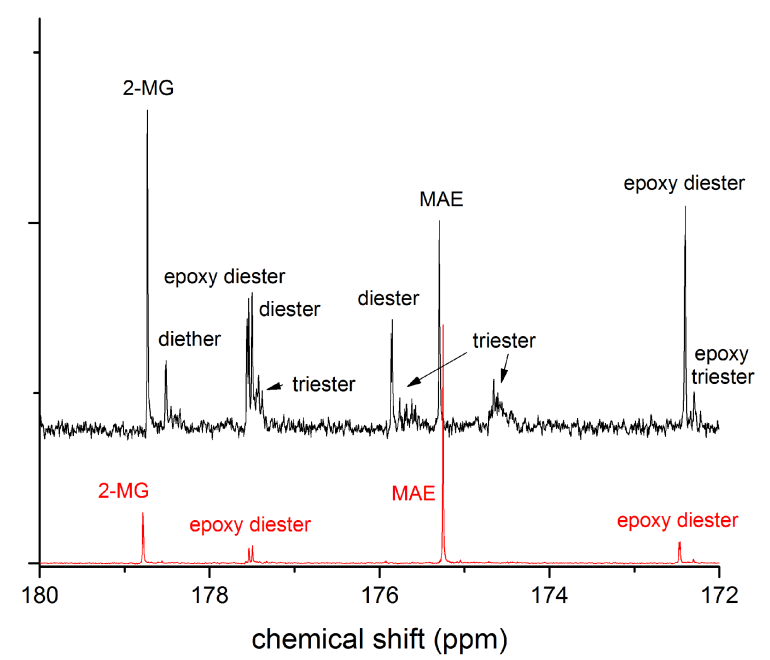

Figure 8. Carbonyl region ${ }^{13} \mathrm{C}$ NMR spectra of early reaction (red trace) and late reaction (black trace) for experiment 4. See Fig. 1 for the molecular species that correspond to the NMR peak labels.

route by which the species formed. For example, the primary diester name assigned to the species formed as shown at the bottom of Fig. 7 reflects that this dimeric species (formed from the reaction of MAE with 2-MG) is connected via a single ester linkage that formed at the primary epoxide carbon of MAE.

For the MAE + MAE reaction (experiment 4), MAE provided the acidity needed for the catalysis of the reaction, while in the MAE + 2-MG reactions (experiments 5 and 7), $2-M G$ provided the acidity. Due to the presence of unavoidable water impurity in the MAE sample, the "neat" MAE reaction system (experiment 4 ) is actually the most complicated one, since MAE can react with itself, water, and 2MG (formed from reaction of MAE with water), which were all present in significant concentrations in experiment 4 (indeed, some of the products of these reactions were identified as participating in further reactions, further adding to the number of observed species). However, with the aid of experiments in which the relative MAE: water : 2-MG amounts were changed (experiments 5 and 6), all of the various products were identified and quantified. The carbonyl region of the ${ }^{13} \mathrm{C}$ NMR spectrum for experiment 4 is shown in Fig. 8 for the two conditions of early reaction (most MAE is still unreacted) and late reaction (most MAE has reacted). During the early phase of the reaction, both the epoxy diester and 2-MG are observed products: 2-MG is formed via hydrolysis from the water impurity in the neat MAE sample, while the epoxy diester is formed from the MAE + MAE mechanism shown in Fig. 5. During the late reaction phase, the epoxy triester is observable (formed from the reaction of the epoxy diester + MAE, as shown in Fig. 6), in addition to two of the species shown in Fig. 7: the primary diether species (formed from MAE reaction with the primary $\mathrm{OH}$ group acting as a nucleophilic group on 2-MG) and the primary diester species. The triester (formed from the reaction of the epoxy diester with 2-MG) is also evident in the late reaction phase spectrum. The tertiary diether species was not observed (were it present in the NMR spectrum, it could be easily distinguished from the primary diether because of its asymmetric structure).

Since the diester species could be formed from either (1) MAE reaction with the carboxylic acid $\mathrm{OH}$ of 2-MG (as shown in Fig. 7) or from (2) hydrolysis of the epoxy diester (as shown in Fig. 9), further experiments were necessary to identify the relevant mechanisms. In order to isolate the $\mathrm{MAE}+2-\mathrm{MG}$ (carboxylic acid nucleophile) diester-forming pathway and to measure the relative nucleophilicity of 2-MG using its carboxylic acid moiety vs. alcohol moiety, an experiment was performed in which 2-MG was placed in excess over the water impurity (experiment 5). Based on NMR quantitation, it was found that the MAE + 2-MG (carboxylic acid nucleophile) and MAE + 2-MG (alcohol nucleophile) reaction pathways are equally facile (of the total 0.19 mole fraction MAE + 2-MG products, 0.10 mole fraction was attributable to the diester product and 0.09 mole fraction was attributable to the diether product). In experiment 6 , additional water was intentionally added to favor the formation of the diester via the hydrolysis of the epoxy diester species. NMR quantitation for this experiment indicated that while 0.03 mole fraction of the diether formed (via the MAE + 2MG (alcohol nucleophile) pathway), 0.24 mole fraction of the diester formed. Since experiment 5 indicated that the MAE + 2-MG (carboxylic acid nucleophile) pathway is expected to produce the diester in the same amounts as the diether, it can be assumed that the extra 0.21 mole fraction of diester formed in experiment 6 is due to the hydrolysis of the epoxy diester. Therefore, it is quite likely that the diester product observed in experiment 4 (and identified in Fig. 8) is produced from both the MAE + 2-MG (carboxylic acid nucleophile) and the epoxy diester $+\mathrm{H}_{2} \mathrm{O}$ reactions.

While the NMR spectra of the diester were previously reported in the context of the acid-catalyzed Fischer esterification of 2-MG (Birdsall et al., 2013), the newly observed epoxy diester and the primary diether species were definitively assigned by using experimental conditions which favored their formation (experiments 4 and 5, respectively), and with the aid of HMQC and HMBC correlation experiments. (These experiments also confirmed that all species were the result of nucleophilic attack on the MAE primary carbon, as expected.) The complete ${ }^{1} \mathrm{H}$ and ${ }^{13} \mathrm{C}$ chemical shift assignments for these species are given in Figs. 1 and 2, respectively. Due to spectral overlap complications, complete triester and epoxy triester assignments were not obtained.

\subsection{Relative nucleophilicity scale}

Using the initial nucleophilic reactant mole fractions $(X$, determined via volume and/or mass measurements) and the fi- 


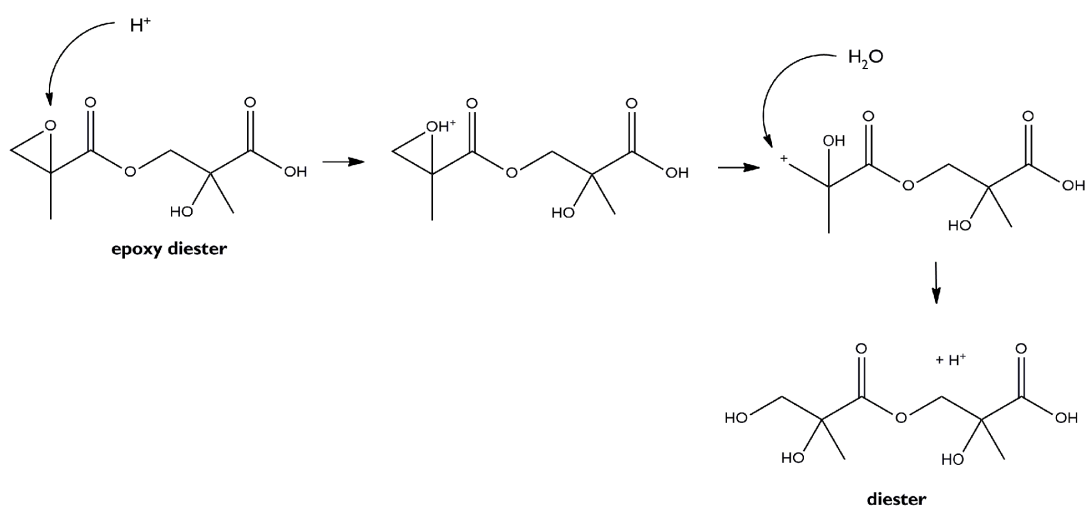

Figure 9. Epoxy diester hydrolysis mechanism.

nal nucleophilic addition product mole fractions ( $Y$, determined via NMR quantitation methods) listed in Table 1, it is possible to determine the relative nucleophilicities (on a molar basis) for the reaction of MAE with the various nucleophiles via Eq. (4):

$\frac{\text { nucleophile } 1 \text { strength }}{\text { nucleophile } 2 \text { strength }}=\frac{\left(Y_{\left.\text {nuc } 1 / X_{\text {nuc 1 }}\right)}\right.}{\left(Y_{\left.\text {nuc } 2 / X_{\text {nuc 2 }}\right)}\right.}$

Note that more than two nucleophiles were present in some of the experiments (which is why the mole fractions in Table 1 do not necessarily sum to unity). It is further possible to relate the nucleophilic strength of all nucleophiles to that of MAE. Starting with experiments 5 and 6, the relative nucleophilic strengths of 2-MG and water to MAE are established (1.2 and 1.6, respectively). Next, the nucleophilic strengths (relative to MAE) of the other nucleophiles are established via their strengths relative to $2-\mathrm{MG}$ and water. In the case of methanol, there are two experiments which can be used to calculate the relative methanol/MAE nucleophilicity; in this case an average value is calculated. Table 3 gives the relative nucleophilic strengths of all studied nucleophiles in their reactions with MAE. In a previous computational study of MAE reactivity, it was predicted that the MAE relative (to water) nucleophilicities for $\mathrm{SO}_{4}^{2-}$ and propanol were 9.8 and 3.6, respectively (Piletic et al., 2013). With conversion of the values given in Table 3 to nucleophilicities relative to water for comparison purposes, the experimental nucleophilicities for $\mathrm{SO}_{4}^{2-}$ and methanol were determined to be 11 and 3.1, respectively, which are in good agreement with the computational predictions. Interestingly, while the relative nucleophilicity of 2-MG using its carboxylic acid moiety was experimentally found to be similar to that of acetic acid, the experimental relative nucleophilicity of 2-MG using its alcohol moiety was found to be significantly less than methanol. Therefore, while the experimental results indicate that the nucleophilicity of multifunctional molecules like 2MG may be approximately viewed as the sum of the nucleophilic strength of separate nucleophilic functional groups, the results also indicate that caution should be used in this simplifying approach.

\section{Atmospheric implications}

\subsection{MAE reaction feasibility on SOA}

Using a previously described framework to estimate the kinetics feasibility of acid-catalyzed epoxide reactions on SOA (Cole-Filipiak et al., 2010), the lifetime, $\tau$, of MAE reaction over a range of atmospherically relevant $\mathrm{pHs}$ was calculated using the equation

$$
\tau=\left[\mathrm{H}^{+}\right]^{-1} k^{-1}
$$

Using the newly determined experimental MAE reaction rate constant results, Eq. (5) yields lifetimes of $2.0 \times 10^{3}$ days at $\mathrm{pH}=4.0,6.2$ days at $\mathrm{pH}=1.5$, and 0.20 days at $\mathrm{pH}=0$. Thus, over a range of atmospherically relevant $\mathrm{pHs}$ (Zhang et al., 2007), the expected lifetime of MAE reaction can range above and below the average lifetime of an aerosol particle (on the order of 2 days). The finding that MAE reaction is kinetically feasible under atmospherically relevant conditions is consistent with the observation of both the hydrolysis product, 2-MG, and - as reported more recently in Lin et al. (2013) - the reactant, MAE, on ambient SOA. While the MAE reaction route to oligomers was found to be about 30 times faster than the Fischer esterification route previously investigated (Birdsall et al., 2013), the MAE reaction is much slower than that of the atmospherically relevant IEPOX-4 species (by a factor of 620, Table 2). A previous atmospheric modeling study of the role of IEPOX and MAE assumed, in the absence of experimental data, that the rate constants for the two species were identical (Pye et al., 2013). Clearly, the much smaller rate constant for MAE will need to be included in future modeling efforts, with the result that modeled MAE reactivity will likely be reduced. 


\subsection{MAE oligomerization mechanism on SOA}

In previous work (Lin et al., 2013), it had been shown that MAE reactions on SOA are capable of producing the kind of 2-MG subunit-containing oligomers identified in environmental chamber experiments (Zhang et al., 2011; A. W. H. Chan et al., 2010a; Nguyen et al., 2011). In this work, we have identified the specific mechanism (epoxy ester chain reaction, as given in Fig. 6) by which MAE reactions lead to such oligomers. While there are potentially two reaction sites for this oligomerization reaction on the epoxide reactant (the primary or tertiary carbon), this work has shown that MAE appears to exclusively react via its primary carbon atom with all studied nucleophiles (including the MAE unit acting as the nucleophile in the oligomerization chain reaction). Therefore, this result leads to the prediction that each higher order oligomer will consist of a single isomer, possessing an extended open-chain structure, owing to the exclusive primary reaction site mechanism.

\subsection{MAE nucleophilic reactions on SOA}

The products and nucleophilic strengths of a number of $\mathrm{MAE}$ + nucleophile reactions were determined in order to assess the likelihood of MAE reaction with a number of atmospherically relevant nucleophilic classes of species: $\mathrm{HOH}$, $\mathrm{ROH}, \mathrm{RC}(=\mathrm{O}) \mathrm{OH}$, and sulfate. The product studies confirmed that MAE can react with each of the classes to form diol, ether, diester, and sulfate ester species, respectively. This work also showed that 2-MG, a dihydroxy acid, can react using both its primary alcoholic $\mathrm{OH}$ (to form an ether product) and carboxylic $\mathrm{OH}$ (to form an ester product) groups as nucleophilic agents. The measured relative nucleophilic strengths of the MAE reaction with the various species indicates that MAE itself is not a particularly strong nucleophile. Thus, it is then straightforward to rationalize why extensive oligomerization has been observed only for laboratory experiments under conditions of low SOA water content: at high SOA water content, water successfully competes with MAE as a nucleophile, and limits oligomerization by direct hydrolysis of MAE or by hydrolysis of the epoxy diester species (as shown in Fig. 9) that is one of the chain carriers in the oligomerization chain reaction. In ambient SOA, other effective nucleophiles may be present in high concentrations (such as alcohols, acids, and inorganic ions), and MAE reactions with these species could also be competitive with hydrolysis and/or oligomerization mechanistic pathways. Therefore, the nature of MAE reaction on SOA is expected to depend sensitively on the chemical composition of the preexisting SOA particle; for cases with heterogeneous SOA compositions, a variety of MAEderived products may be expected, with these reactions likely outcompeting the oligomerization pathways (due to MAE's mediocre nucleophilic strength and relatively low concentration compared to such abundant nucleophiles as water and sulfate). While the nitrate nucleophile was not directly studied in these experiments, because its relative nucleophilicity has been found to be similar to sulfate for reactions with isoprene-derived epoxides (Darer et al., 2011), it is expected for MAE reactions that sulfate and nitrate would have similarly nucleophilicities. While hetero-oligomers, formed from cross reactions of MAE with other atmospherically relevant epoxides (such as IEPOX and 2-methyl-3-buten-2-ol-derived (Zhang et al., 2014) epoxides), might be formed on ambient SOA, these epoxides are also expected to have mediocre nucleophilic strength (they are probably more similar to 2-MG than to methanol), and these reactions would also probably not be competitive with reactions involving more abundant nucleophiles. Thus far, field studies have identified only two likely MAE reaction products, 2-MG and the diester (Jaoui et al., 2008), which are likely formed from hydrolysis of MAE and the reaction of MAE with 2-MG, respectively. The formation of the diester from the epoxy diester hydrolysis reaction on ambient SOA is less likely since conditions favoring hydrolysis would also favor the formation of 2-MG, which would probably lead to the dominance of the MAE + 2-MG diester-forming pathway.

\section{Conclusions}

The present results suggest that acid-catalyzed nucleophilic addition to MAE is much slower than the analogous IEPOX4 reaction, but, nonetheless, is expected to be kinetically feasible in the atmosphere, particularly on more acidic SOA. The specific mechanism by which MAE leads to oligomers was identified (epoxide chain reaction), and the reactions of MAE with a number of atmospherically relevant nucleophiles were also investigated. Because the nucleophilic strengths of water, sulfate, alcohols (including 2-MG), and acids (including MAE and 2-MG) in their reactions with MAE were found to be of a similar magnitude, it is expected that a diverse variety of MAE + nucleophile product species may be formed on ambient SOA. Thus, the results indicate that epoxide chain reaction oligomerization will be limited by the presence of high concentrations of non-epoxide nucleophiles (such as water); this finding is consistent with previous environmental chamber investigations of the relative humidity dependence of 2-MG-derived oligomerization processes and suggests that extensive oligomerization may not be likely on ambient SOA because of other competitive MAE reaction mechanisms.

Acknowledgements. This work was supported by the National Science Foundation under grant no. 1153861.

Edited by: V. Faye McNeill 


\section{References}

Birdsall, A. W., Zentner, C. A., and Elrod, M. J.: Study of the kinetics and equilibria of the oligomerization reactions of 2-methylglyceric acid, Atmos. Chem. Phys., 13, 3097-3109, doi:10.5194/acp-13-3097-2013, 2013.

Braun, S, Kalinowski, H.-O., and Berger, S.: 200 and more NMR experiments, Wiley-VCH, Weinheim, 1998.

Carlton, A. G., Wiedinmyer, C., and Kroll, J. H.: A review of secondary organic aerosol (SOA) formation from isoprene, Atmos. Chem. Phys., 9, 4987-5005, doi:10.5194/acp-9-4987-2009, 2009.

Chan, A. W. H., Chan, M. N., Surratt, J. D., Chhabra, P. S., Loza, C. L., Crounse, J. D., Yee, L. D., Flagan, R. C., Wennberg, P. O., and Seinfeld, J. H.: Role of aldehyde chemistry and $\mathrm{NO}_{\mathrm{x}}$ concentrations in secondary organic aerosol formation, Atmos. Chem. Phys., 10, 7169-7188, doi:10.5194/acp-10-7169-2010, 2010.

Chan, M. N., Surratt, J. D., Claeys, M., Edgerton, E. S., Tanner, R. L., Shaw, S. L., Zheng, M., Knipping, E. M., Eddingsaas, N. C., Wennberg, P. O., and Seinfeld, J. H.: Characterization and quantification of isoprene-derived epoxydiols in ambient aerosol in the southeastern United States, Environ. Sci. Technol., 44, 45904596, 2010.

Clegg, S. L., Brimblecombe, P., and Exler, A. S.: A thermodynamic model of the system $\mathrm{H}^{+}-\mathrm{NH}_{4}^{+}-\mathrm{SO}_{4}^{2-}-\mathrm{NO}_{3}^{-}-\mathrm{H}_{2} \mathrm{O}$ at tropospheric temperatures, J. Phys. Chem. A, 102, 2137-2154, 1998.

Cole-Filipiak, N. C., O'Connor, A. E., and Elrod, M. J.: Kinetics of the hydrolysis of atmospherically relevant isoprene-derived hydroxy epoxides, Environ. Sci. Technol., 44, 6718-6723, 2010.

Costa, V. V., da Silva Rocha, K. A., Kozhevnikov, I. V., Kozhevnikova, E. F., and Gusevskaya, E. V.: Heteropoly acid catalysts for the synthesis of fragrance compounds from biorenewables: isomerization of limonene oxide, Catal. Sci. Technol., 3, 244-250, doi:10.1039/c2cy20526b, 2013.

Darer, A. I., Cole-Filipiak, N. C., O'Connor, A. E., and Elrod, M. $\mathrm{J} .:$ Formation and stability of atmospherically relevant isoprenederived organosulfates and organonitrates, Environ. Sci. Technol., 45, 1895-1902, 2011.

Eddingsaas, N. C., VanderVelde, D. G., and Wennberg, P. O.: Kinetics and products of the acid-catalyzed ring-opening of atmospherically relevant butyl epoxy alcohols, J. Phys. Chem. A, 114, 8106-8113, doi:10.1021/Jp103907c, 2010.

Edney, E., Kleindienst, T., Jaoui, M., Lewandowski, M., Offenberg, J., Wang, W., and Claeys, M.: Formation of 2methyl tetrols and 2-methylglyceric acid in secondary organic aerosol from laboratory irradiated isoprene/NO/SO/air mixtures and their detection in ambient PM samples collected in the eastern United States, Atmos. Environ., 39, 5281-5289, doi:10.1016/j.atmosenv.2005.05.031, 2005.

Gómez-González, Y., Surratt, J. D., Cuyckens, F., Szmigielski, R., Vermeylen, R., Jaoui, M., Lewandowski, M., Offenberg, J. H., Kleindienst, T. E., Edney, E. O., Blockhuys, F., Van Alsenoy, C., Maenhaut, W., and Claeys, M.: Characterization of organosulfates from the photooxidation of isoprene and unsaturated fatty acids in ambient aerosol using liquid chromatography/(-) electrospray ionization mass spectrometry, J. Mass Spectrom., 43, 371-382, doi:10.1002/jms.1329, 2008.

Grill, J. M., Ogle, J. W., and Miller, S. A.: An Efficient and Practical System for the Catalytic Oxidation of Alcohols, Aldehydes, and $\alpha, \beta$-Unsaturated Carboxylic Acids, The Journal of Organic Chemistry, 71, 9291-9296, doi:10.1021/jo0612574, 2006.

Hallquist, M., Wenger, J. C., Baltensperger, U., Rudich, Y., Simpson, D., Claeys, M., Dommen, J., Donahue, N. M., George, C., Goldstein, A. H., Hamilton, J. F., Herrmann, H., Hoffmann, T., Iinuma, Y., Jang, M., Jenkin, M. E., Jimenez, J. L., KiendlerScharr, A., Maenhaut, W., McFiggans, G., Mentel, T. F., Monod, A., Prevot, A. S. H., Seinfeld, J. H., Surratt, J. D., Szmigielski, R., and Wildt, J.: The formation, properties and impact of secondary organic aerosol: current and emerging issues, Atmos. Chem. Phys., 9, 5155-5236, doi:10.5194/acp-9-5155-2009, 2009.

Hatch, L. E., Creamean, J. M., Ault, A. P., Surratt, J. D., Chan, M. N., Seinfeld, J. H., Edgerton, E. S., Su, Y., and Prather, K. A.: Measurements of isoprene-derived organosulfates in ambient aerosols by aerosol time-of-flight mass spectrometry - part 1: single particle atmospheric observations in Atlanta, Environ. Sci. Technol., 45, 5105-5111, doi:10.1021/es103944a, 2011a.

Hatch, L. E., Creamean, J. M., Ault, A. P., Surratt, J. D., Chan, M. N., Seinfeld, J. H., Edgerton, E. S., Su, Y., and Prather, K. A.: Measurements of isoprene-derived organosulfates in ambient aerosols by aerosol time-of-flight mass spectrometry - part 2: temporal variability and formation mechanisms, Environ. Sci. Technol., 45, 8648-8655, doi:10.1021/es2011836, $2011 \mathrm{~b}$.

Hu, K. S., Darer, A. I., and Elrod, M. J.: Thermodynamics and kinetics of the hydrolysis of atmospherically relevant organonitrates and organosulfates, Atmos. Chem. Phys., 11, 8307-8320, doi:10.5194/acp-11-8307-2011, 2011.

Jaoui, M., Edney, E. O., Kleindienst, T. E., Lewandowski, M., Offenberg, J. H., Surratt, J. D., and Seinfeld, J. H.: Formation of secondary organic aerosol from irradiated $\alpha$-pinene/toluene/ $\mathrm{NO}_{\mathrm{X}}$ mixtures and the effect of isoprene and sulfur dioxide, J. Geophys. Res., 113, D09303, doi:10.1029/2007jd009426, 2008.

Lin, Y.-H., Zhang, Z., Docherty, K. S., Zhang, H., Budisulistiorini, S. H., Rubitschun, C. L., Shaw, S. L., Knipping, E. M., Edgerton, E. S., Kleindienst, T. E., Gold, A., and Surratt, J. D.: Isoprene epoxydiols as precursors to secondary organic aerosol formation: acid-catalyzed reactive uptake studies with authentic compounds, Environ. Sci. Technol., 46, 250-258, doi:10.1021/es202554c, 2012.

Lin, Y.-H., Zhang, H., Pye, H. O. T., Zhang, Z., Marth, W. J., Park, S., Arashiro, M., Cui, T., Budisulistiorini, S. H., Sexton, K. G., Vizuete, W., Xie, Y., Luecken, D. J., Piletic, I. R., Edney, E. O., Bartolotti, L. J., Gold, A., and Surratt, J. D.: Epoxide as a precursor to secondary organic aerosol formation from isoprene photooxidation in the presence of nitrogen oxides, Proc. Natl. Acad. Sci., 110, 6718-6723, doi:10.1073/pnas.1221150110, 2013.

Minerath, E. C. and Elrod, M. J.: Assessing the potential for diol and hydroxy sulfate ester formation from the reaction of epoxides in tropospheric aerosols, Environ. Sci. Technol., 43, 1386-1392, doi:10.1021/es8029076, 2009.

Minerath, E. C., Schultz, M. P., and Elrod, M. J.: Kinetics of the reactions of isoprene-derived epoxides in model tropospheric aerosol solutions, Environ. Sci. Technol., 43, 8133-8139, doi:10.1021/es902304p, 2009.

Nguyen, T. B., Roach, P. J., Laskin, J., Laskin, A., and Nizkorodov, S. A.: Effect of humidity on the composition and yield of isoprene photooxidation secondary organic aerosol, Atmos. Chem. Phys., 11, 6931-6944, doi:10.5194/acpd-11-9217-2011, 2011. 
Paulot, F., Crounse, J. D., Kjaergaard, H. G., Kurten, A., St. Clair, J. M., Seinfeld, J. H., and Wennberg, P. O.: Unexpected epoxide formation in the gas-phase photooxidation of isoprene, Science, 325, 730-733, doi:10.1126/science.1172910, 2009.

Piletic, I. R., Edney, E. O., and Bartolotti, L. J.: A computational study of acid catalyzed aerosol reactions of atmospherically relevant epoxides, Phys. Chem. Chem. Phys., 15, 18065, doi:10.1039/c3cp52851k, 2013.

Pye, H. O. T., Pinder, R. W., Piletic, I. R., Xie, Y., Capps, S. L., Lin, Y.-H., Surratt, J. D., Zhang, Z., Gold, A., Luecken, D. J., Hutzell, W. T., Jaoui, M., Offenberg, J. H., Kleindienst, T. E., Lewandowski, M., and Edney, E. O.: Epoxide Pathways Improve Model Predictions of Isoprene Markers and Reveal Key Role of Acidity in Aerosol Formation, Environ. Sci. Technol., 47, 11056-11064, doi:10.1021/es402106h, 2013.

Surratt, J. D., Murphy, S. M., Kroll, J. H., Ng, N. L., Hildebrandt, L., Sorooshian, A., Szmigielski, R., Vermeylen, R., Maenhaut, W., Claeys, M., Flagan, R. C., and Seinfeld, J. H.: Chemical Composition of Secondary Organic Aerosol Formed from the Photooxidation of Isoprene, J. Phys. Chem. A, 110, 9665-9690, doi:10.1021/jp061734m, 2006.

Surratt, J. D., Kroll, J. H., Kleindienst, T. E., Edney, E. O., Claeys, M., Sorooshian, A., Ng, N. L., Offenberg, J. H., Lewandowski, M., Jaoui, M., Flagan, R. C., and Seinfeld, J. H.: Evidence for organosulfates in secondary organic aerosol, Environ. Sci. Technol., 41, 517-527, 2007.

Surratt, J. D., Chan, A. W. H., Eddingsaas, N. C., Chan, M., Loza, C. L., Kwan, A. J., Hersey, S. P., Flagan, R. C., Wennberg, P. O., and Seinfeld, J. H.: Reactive intermediates revealed in secondary organic aerosol formation from isoprene, Proc. Natl. Acad. Sci., 107, 6640-6645, 2010.
Szmigielski, R., Surratt, J. D., Vermeylen, R., Szmigielska, K., Kroll, J. H., Ng, N. L., Murphy, S. M., Sorooshian, A., Seinfeld, J. H., and Claeys, M.: Characterization of 2-methylglyceric acid oligomers in secondary organic aerosol formed from the photooxidation of isoprene using trimethylsilylation and gas chromatography/ion trap mass spectrometry, J. Mass Spectrom., 42, 101-116, doi:10.1002/jms.1146, 2007.

Whalen, D. L.: Mechanisms of hydrolysis and rearrangements of epoxides, Adv. Phys. Org. Chem., 40, 247-298, 2005.

Zhang, H., Surratt, J. D., Lin, Y. H., Bapat, J., and Kamens, R. M.: Effect of relative humidity on SOA formation from isoprene/NO photooxidation: enhancement of 2-methylglyceric acid and its corresponding oligoesters under dry conditions, Atmos. Chem. Phys., 11, 6411-6424, doi:10.5194/acp-11-6411-2011, 2011.

Zhang, H., Zhang, Z., Cui, T., Lin, Y.-H., Bhathela, N. A., Ortega, J., Worton, D. R., Goldstein, A. H., Guenther, A., Jimenez, J. L., Gold, A., and Surratt, J. D.: Secondary Organic Aerosol Formation via 2-Methyl-3-buten-2-ol Photooxidation: Evidence of Acid-Catalyzed Reactive Uptake of Epoxides, Environ. Sci. Technol. Lett., 1, 242-247, doi:10.1021/ez500055f, 2014.

Zhang, Q., Jimenez, J. L., Worsnop, D. R., and Canagaratna, M.: A case study of urban particle acidity and its influence on secondary organic aerosol, Environ. Sci. Technol., 41, 3213-3219, 2007. 